\title{
Movilización del concepto ambiente en estudiantes de grado sexto
}

\section{Mobilization of the environment concept on sixth grade students}

Jenny Natalia Fonseca Rincón*

Ricardo Molano Carrera**

Recepción: 16 de Abril de 2016.

Aceptación: 2 de Noviembre de 2016.

Artículo de Investigación

\section{Resumen}

Se presentan los resultados preliminares del proyecto Movilización del concepto ambiente en estudiantes de grado sexto, específicamente los resultados de la exploración conceptual sobre ambiente. El proyecto tiene como objetivo el diseño y construcción de una propuesta pedagógica y didáctica que contribuya a la movilización de las concepciones de ambiente instaladas en estudiantes hacia una visión sistémica del mismo y que sea pertinente con las intencionalidades formativas del Proyecto Ambiental Escolar (PRAE). El proyecto se lleva a cabo bajo el paradigma Socio crítico, con enfoque investigativo Cualitativo y una metodología Investigación acción, con una muestra de 29 estudiantes con edades entre 11 y 13 años pertenecientes a uno de los tres grados sexto de la Institución Educativa Técnica Enrique Olaya Herrera del Municipio de Guateque. Veintiún (21) estudiantes realizaron un dibujo y un texto explicativo del mismo, a
* Institución Educativa Enrique Olaya Herrera, Boyacá Colombia z730836@hotmail.com ** Universidad Pedagógica y Tecnológica de Colombia, Boyacá Colombia ziruma01@gmail.com

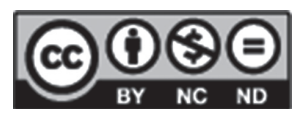


partir de la pregunta ¿para ti qué es el ambiente? La categorización de las respuestas, permitió concluir que los resultados coinciden con lo reportado en la revisión de antecedentes: los estudiantes no establecen interacciones entre componentes del ambiente $y$ centran sus respuestas en una visión antropocéntrica y naturalista del

\section{Abstract}

The preliminary results of the project Mobilization of the environment concept in sixth grade students are presented, specifically the results of the conceptual exploration about the environment. The objective of the project is the design and construction of a pedagogical and didactic proposal that contributes to the mobilization of the concepts of environment installed in students towards a systemic vision of the same and that is pertinent to the formative intentions of the School Environmental Project (SEP). The project is carried out under the socio critical paradigm, with a qualitative research approach and research action methodology, with a sample of 29 students between the ages of 11 and 13 belonging to one of the three sixth grade groups of the "Enrique Olaya Herrera" Educational Institution in mismo. Estos resultados ratifican la necesidad de construir una propuesta pedagógica y didáctica que permita la comprensión del concepto ambiente desde una visión sistémica.

Palabras clave: educación, movilización de conceptos, ambiente, visión sistémica, educación ambiental.

Guateque (Boyacá, Colombia). Twentyone (21) students made a drawing and an explanatory text, based on the question, what is the environment for you? The categorization of the answers allowed us to conclude that the results coincide with what was reported in the background check: the students do not establish interactions between components of the environment and focus their responses on an anthropocentric and naturalistic vision of the same. These results confirm the need to build a pedagogical and didactic proposal that allows the understanding of the concept environment from a systemic vision.

Keywords: education, mobilization of concepts, environment, systemic vision, environmental education. 


\section{Introducción}

El proyecto Movilización del Concepto Ambiente en estudiantes de grado sexto se origina a partir de la necesidad de construir y unificar conceptualmente aspectos básicos del Proyecto Ambiental Escolar (PRAE) de la Institución Educativa Técnica Enrique Olaya Herrera, del municipio de Guateque. A partir del hecho que no existe una propuesta didáctica y pedagógica en este grado que permita identificar y movilizar conceptos básicos de las Ciencias Naturales y de la Educación Ambiental, como es el caso del concepto ambiente, se estableció la pregunta de investigación: ¿Cómo el diseño y aplicación de una estrategia pedagógica y didáctica contribuye a la movilización del concepto ambiente hacia una visión sistémica en estudiantes de grado sexto de la IET Enrique Olaya Herrera del municipio de Guateque?

En el presente artículo se presentan los resultados parciales del diseño, aplicación y evaluación de la propuesta mencionada anteriormente, específicamente la categorización inicial del concepto de ambiente de los estudiantes. El proyecto se realizó bajo el paradigma Socio crítico, con un enfoque investigativo cualitativo y con el método de investigación acción.

La categorización inicial de los conceptos de los estudiantes, permitió el planteamiento y aplicación de la propuesta pedagógica y didáctica, cuyos resultados se están sistematizando y analizando al momento de redactar este escrito. A partir de la revisión de los antecedentes y el marco teórico, se construyen los referentes teóricos que permiten la categorización y el análisis de la información obtenida gracias a la propuesta metodológica planteada. Los referentes teóricos se centran en la movilización de los conceptos como propuesta didáctica que denota el aprendizaje de los estudiantes y la riqueza de la visión sistémica de ambiente al desarrollo de una nueva forma de relacionarse con el entorno. Finalmente, los resultados y el análisis preliminar permiten evidenciar la importancia del diseño y aplicación de propuestas pedagógicas y didácticas que tengan en cuenta los marcos conceptuales iniciales de los estudiantes.

El diseño de la propuesta ha permitido reflexionar acerca de las prácticas llevadas a cabo en el aula, especialmente a la hora de entender, ¿por qué los estudiantes no aprenden lo que los docentes les enseñan? Al trabajar sobre la movilización de concepciones, se asume el constructivismo como modelo pedagógico haciendo explícita una de las posibles causas de no lograr el aprendizaje deseado: el desconocer que cada individuo construye su propio conocimiento, nadie lo puede transmitir directamente (Giordan, 1996; Rosas y Sebastián, 2008). Creer que el hecho de enseñar una temática implica que el estudiante la aprenda, constituye una barrera para que los aprendizajes se hagan efectivos a pesar de las largas horas dedicadas a estos procesos.

De aquí la importancia de guiar al estudiante en la construcción de su
El proyecto Movilización del Concepto Ambiente en estudiantes de grado sexto se origina a partir de la necesidad de construir y unificar conceptualmente aspectos básicos del Proyecto Ambiental Escolar (PRAE) de la Institución Educativa Técnica Enrique Olaya Herrera, del municipio de Guateque. 
Infortunadamente, la falta de unidad sobre el concepto ambiente es constante desde las Instituciones Educativas, hasta niveles técnicos y profesionales. propio conocimiento, ya que movilizar sus concepciones le permite entender y relacionarse con la realidad en la que se encuentra inmerso. También es importante para los docentes tener en cuenta las consideraciones de tipo afectivo: la predisposición a querer aprender, una necesidad de movilizar sus concepciones hacia otras más pertinentes ante una situación dada.

La movilización del concepto ambiente hacia una visión sistémica, permite crear las condiciones pedagógicas y didácticas para que los docentes asuman el reto de reconocer el aprendizaje como una aventura individual pero a partir de experiencias comunes retadoras que motiven a apropiarse de nuevos conocimientos.

\section{Antecedentes}

A partir de la búsqueda y análisis de diferentes tesis de grado a nivel de Maestría y artículos investigativos publicados en Internet, se establecieron debilidades en los marcos conceptuales relacionados con la educación ambiental (EA) tanto en estudiantes, docentes y en directivos (Flórez, 2012; Molano, 2011; Niño, 2013). Los problemas conceptuales en docentes y directivos dificultan aspectos como la proyección hacia la comunidad, la flexibilidad curricular y el componente investigativo que debe desarrollar la EA mientras que en los estudiantes, dificultan la comprensión y, por lo tanto, en el uso que le puedan dar al conocimiento en diferentes contextos.

Ahora bien, dentro de los conceptos básicos de las Ciencias Naturales y la
Educación Ambiental, se encuentra el concepto de ambienteya que fundamenta procesos educativos en todos los niveles, así como Políticas Ambientales y Planes de Gestión Ambiental a nivel de desarrollo económico y empresarial. Una unidad conceptual alrededor del ambiente desde la visión de sistema, permite a los estudiantes, y a la sociedad en general, entender las relaciones que el ser humano establece con su medio biofísico, social y cultural.

Infortunadamente, la falta de unidad sobre el concepto ambiente es constante desde las Instituciones Educativas, hasta niveles técnicos y profesionales. En Colombia, a nivel de enseñanza Básica y Media, Álvarez (2015) en su Tesis de Maestría Concepciones de ambiente en estudiantes de educación media del Colegio Carlos J. Huelgos de Ibagué, estableció que la comprensión de las concepciones de ambiente en los estudiantes, es base fundamental en la propuesta e implementación de estrategias que tengan real incidencia en la Educación Ambiental. Para identificar estas concepciones, se utilizaron las representaciones gráficas sobre el tema. Su análisis determinó que los estudiantes de grado once conciben el ambiente como objeto, ya que los principales componentes del ambiente se limitan a los recursos naturales básicos, pero porque de ellos depende el bienestar humano, minimizando las necesidades de los ecosistemas en su complejidad.

En la educación superior persisten las dificultades en conceptualizar el ambiente como un sistema. En Argentina, Gonzáles (s.f.) analizó 92 respuestas de estudiantes de Educación 
Superior en Buenos Aires sobre las concepciones de medio ambiente. La población seleccionada correspondió a alumnos pertenecientes al primer y segundo año de la carrera de Técnico Superior en Ecología de un Centro Educativo de Nivel Terciario, y de segundo año de la carrera de Licenciatura en Ciencias del Ambiente de una universidad. Al analizar las respuestas, la autora destaca que para todos los grupos de alumnos, aun en aquellos que han cursado un año de estudios, la mayoría de respuestas corresponden a categorías que describen el ambiente ya sea como un lugar, o un lugar que contiene seres vivos, o también como un lugar que contiene seres vivos y gente y donde no se evidencia la presencia de interacciones entre los componentes enunciados por los estudiantes.

A nivel profesional, más específicamente en docentes en ejercicio y en formación, Menegaz, Cordero y Mengascini (2012) en su artículo denominado Sistematización de una experiencia de educación ambiental en la formación docente continua: representaciones, ambiente y análisis colaborativo, presentan los resultados de la exploración conceptual acerca del ambiente, presentan los resultados de las explicitaciones de las representaciones de ambiente realizadas durante talleres entre los años 2008 y 2010, con aproximadamente 50 docentes de diferentes niveles educativos en la provincia de Buenos Aires. El concepto ambiente fue seleccionado por las autoras, ya que: "incide en la definición de los problemas ambientales y en la perspectiva educativa a partir de la cual se diseña la situación de enseñanza" (p. 663). Para revelar las representaciones sobre ambiente, se les pidió a los participantes realizar un dibujo cuyas imágenes fueron analizadas de manera global, reconociendo las diferentes escalas y temáticas; se analizaron también sus componentes e interacciones, elaborando categorías emergentes para su descripción y comparación.

La categorización de las imágenes permitió concluir que estas muestran posturas compatibles con la naturalista, biológica y biológico-física, por un lado; y con la antropocéntrica, que ve a la naturaleza como recurso o fuente de recursos o como un lugar para vivir, por el otro.

A nivel profesional, durante la realización del Diplomado Educación Ambiental y contexto institucional: Estrategia transversal, para la cualificación de la gestión ambiental y su proyección, en el Departamento de Boyacá, dirigido a los profesionales, técnicos y extensionistas de la Corporación Autónoma Regional de Boyacá - CORPOBOYACÁ, se realizó una exploración conceptual acerca de cuatro conceptos básicos: Ambiente, Educación Ambiental, Participación y Proyección Comunitaria. Esta exploración inicial permitió identificar la evolución de la apropiación conceptual planteada dentro del diplomado. Para la caracterización del concepto ambiente, se establecieron cuatro categorías: a) aproximación antropocentrista (con subcategorías Ser Humano- centro, Ser HumanoEntorno; Ser Humano; Medio o lugar) b) Naturalista (con dos subcategorías: elementos naturales; visión sistémica en lo natural), c) Ecológica (Ecosistémica Natural), y, d) Visión sistémica (con dos subcategorías: Aproximación Social y
La población seleccionada correspondió a alumnos pertenecientes al primer $\mathrm{y}$ segundo año de la carrera de Técnico Superior en Ecología de un Centro Educativo de Nivel Terciario, y de segundo año de la carrera de Licenciatura en Ciencias del Ambiente de una universidad. 
Los problemas conceptuales en torno al ambiente, se ven reforzados en estudiantes y en los mismos docentes por la falta de consistencia del mismo dentro de los libros de texto.
Elementos del Ambiente Yuxtapuestos). Los resultados demuestran que los aspectos socioculturales son poco reconocidos, y que prevalece una concepción naturalista de carácter conservacionista. Adicionalmente, el concepto de interacción se encuentra ausente, lo que dificulta la comprensión del ambiente como el resultado de la dinámica entre naturaleza, sociedad y la cultura.

Los problemas conceptuales en torno al ambiente, se ven reforzados en estudiantes y en los mismos docentes por la falta de consistencia del mismo dentro de los libros de texto. En el estudio de García (S.F), El concepto de ambiente en los libros de texto, se analizó una población de 30 libros de Ciencias Naturales y Medio Ambiente utilizados en grados sexto y octavo en la Ciudad de Medellín, determinando que el 97 $\%$ de los textos presentan el concepto de ambiente desde una visión físiconatural, es decir, como lugar o espacio en el que se dan diversas relaciones entre los seres vivos y los no vivos, y solo en un $3 \%$ de los textos (correspondiente a una de las muestras analizadas) se brinda una visión sistémica.

Estas dificultades conceptuales justifican la realización del presente proyecto. Una unidad acerca del concepto ambiente desde la visión sistémica, requiere de una movilización de las concepciones que conforman el marco conceptual. Este proceso de construcción de pensamiento se lleva a cabo en todas las áreas del conocimiento, Castaño (2014) y Venegas (2015) enfatizan la importancia de la movilización de concepciones en docentes. Ambos autores se refieren a ellas como el marco de referencia a partir del cual los docentes comprenden y planifican sus actuaciones en el aula y que se hacen evidentes en la relación entre el "decir" y el "hacer". Además, reconocen que estas concepciones no siempre son conscientes, y por ello se deben confrontar desde la teoría y la práctica. La inmovilidad de las concepciones conlleva a: "al conformismo y al anquilosamiento de la práctica docente. Para que se produzca una evolución, [...] el maestro debe hacer una revisión de sus creencias con el propósito de movilizarlas y transformarlas” (Castaño, 2014, p. 11).

\section{Marco teórico}

El diseñar una propuesta pedagógica requiere que el docente adopte una posición pedagógica definida: cuál es su idea de aprendizaje, cómo concibe el papel del estudiante y del docente dentro del proceso, cómo será la forma de evaluar. Ante esta situación, nace la necesidad de reflexionar e investigar qué es lo que pasa en el aula, si los supuestos pedagógicos asumidos consciente o inconscientemente por el educador son pertinentes o no. Esta reflexión es también motivante para el educador: proponer y evaluar diferentes experiencias lo salva de la rutina de enseñar lo mismo, de la misma forma año tras año, con resultados generalmente insatisfactorios.

El proyecto Movilización del Concepto Ambiente en Estudiantes de Grado Sexto, permite el desarrollo de una propuesta pedagógica didáctica basada en dos grandes pilares: 
1. La movilización de conceptos como una forma de adquirir nuevos conocimientos.

2. El concepto ambiente desde una visión sistémica definido por la interacción de diferentes componentes (naturales, sociales y culturales).

\section{La movilización de conceptos}

El presente proyecto está basado en un modelo pedagógico constructivista, lo cual implica que el docente reconoce que no posee el conocimiento ni lo puede transmitir a un discípulo. Para entender el aprendizaje como movilización de concepciones se tendrá en cuenta lo que Giordan y de Vecchi (1988), denominan estructura conceptual, es decir estructuras mentales en las que: "se insertan y organizan los conocimientos apropiados y las operaciones mentales" (p. 88) que una persona domina. Cabe destacar que los conocimientos se insertan y organizan, no se acumulan ni entran pasivamente a formar parte de la misma. La construcción de estas estructuras involucran diversas fuentes de conocimiento: la escuela, los medios de comunicación, la interacción social $\mathrm{y}$ las experiencias cotidianas.

Dentro de las estructuras conceptuales se encuentran las concepciones de quien aprende. Una concepción es definida por los mismos autores como: "un conjunto de ideas coordinadas e imágenes coherentes, explicativas, utilizadas por las personas que aprenden para razonar frente a situaciones problema [...] este conjunto traduce una estructura mental subyacente responsable de estas manifestaciones contextuales" (p. 103).
La movilización de concepciones puede ser producida ante situaciones de aprendizaje retadoras, que demuestren que las concepciones contenidas en la estructura conceptual no son pertinentes para comprender la realidad, obligándolas a adaptarse con el fin de poder integrar el conocimiento suplementario. No hay pues destrucción, sino transformación de las estructuras.

\section{Concepto de ambiente desde una visión sistémica}

El concepto ambiente ha sufrido múltiples transformaciones a lo largo del tiempo y de acuerdo con los paradigmas sociales, definidos por Capra (2003) como: "una constelación de conceptos, valores, percepciones y prácticas compartidos por una comunidad, que conforman una particular visión de la realidad que, a su vez, es la base del modo en que dicha comunidad se organiza" (p. 26). En esta definición, es importante resaltar la relación entre los conceptos y la interpretación de la realidad. González (2006) hace énfasis en esta correspondencia cuando afirma que estas construcciones conceptuales son:

[...] herramientas típicamente humanas producidas en un contexto espacio- temporal y culturalmente definido que las condiciona, limitandosucapacidad de percepción estratégica y global, si no logran desprenderse de las sobredeterminaciones generadas en intereses coyunturales, que las mantienen vigentes, aunque su capacidad explicativa sea cada vez más precaria. (p. 18).
El presente proyecto está basado en un modelo pedagógico constructivista, lo cual implica que el docente reconoce que no posee el conocimiento ni lo puede transmitir a un discípulo. 
Claramente este método de pensamiento tuvo incidencia en la vida de la sociedad en general, y no solo a nivel del desarrollo de la ciencia.
En este marco teórico se tienen en cuenta dos paradigmas sociales: El Paradigma del pensamiento positivista mecanicista y el Paradigma pensamiento sistémico.

\section{El Paradigma del pensamiento} positivista mecanicista: surge en Europa a partir del SigloXV en el período histórico denominado Modernismo, y domina el pensamiento occidental a partir del desarrollo de la ciencia y de los procesos políticos económicos y sociales de ese momento hasta nuestros días. La revolución copernicana, los métodos científicos desarrollados por Galileo, culminan en las propuestas de René Descartes, quien con la creación de su método de pensamiento analítico propone que para la comprensión del todo es necesario su descomposición en sus partes, así el entendimiento de cómo funcionan las partes da cuenta del todo.

Claramente este método de pensamiento tuvo incidencia en la vida de la sociedad en general, y no solo a nivel del desarrollo de la ciencia. A la larga, esta visión ha dominado la construcción de la realidad hasta nuestros días, tal como la resume Capra (2003):

Dicho paradigma consiste en una enquistada serie de ideas y valores, entre los que podemos citar la visión del universo como un sistema mecánico compuesto de piezas, la del cuerpo humano como una máquina, la de la vida en sociedad como una lucha competitiva por la existencia, la creencia en el progreso material ilimitado a través del crecimiento económico y tec- nológico y, no menos importante, la convicción de que una sociedad en la que la mujer está por doquier sometida al hombre, no hace sino seguir las leyes naturales. (p. 27).

Esta separación entre el observador (hombre) y el objeto observado (naturaleza), tiene como consecuencia colocar al ser humano por encima de la naturaleza, y a la vez que logra mejorar la percepción y la catalogación de los otros "reinos", también justifica el poder transformador y el dominio sobre ellos con el fin de lograr una rentabilidad (Carrizosa, 2000).

Paradigma pensamiento sistémico: pasarían varios siglos para entender que la complejidad de la realidad no es posible de abarcar a partir de un pensamiento lineal que separa, divide. Las bases de este paradigma se habían establecido desde la década de 1930, especialmente en disciplinas como la sicología, la biología y, especialmente, la ecología. En estos campos se hizo evidente la necesidad de pensar en función de conectividad, relaciones y contexto. En términos generales, y teniendo en cuenta la obra de Capra (2003), La trama de la vida, las principales características del pensamiento sistémico se pueden resumir como:

La comprensión de los sistemas, por ejemplo los sistemas vivos, no puede ser realizada a partir de sus partes. Es necesaria tener en cuenta un sistema como una totalidad integrada cuyas propiedades no son la sumatoria de las propiedades de sus partes más pequeñas. De aquí surge el concepto de propiedades esenciales o sistémicas, es decir 
aquellas que tiene el todo pero no sus partes. (p. 57).

De acuerdo con Ángel (2013), los problemas ambientales son inherentes a la evolución humana, ya que desde que los primeros homínidos tuvieron la capacidad de organizarse para proveer la caza necesaria para su sustento o de seleccionar las plantas que a través de la agricultura propagó en detrimento de otras cuyo nicho ecológico fue desplazado, el equilibrio ecosistémico empezó a variar. A diferencia de otros seres vivos que logran adaptarse al medio a través de los cambios genéticos, el hombre lo hace mediante la cultura y la sociedad representadas en: "la adaptación instrumental, la organización social y la elaboración simbólica. La tecnología, la organización social y el símbolo deberían tratarse como formas adquiridas en el proceso evolutivo de la naturaleza” (p. 72). Mientras la solución a las problemáticas ambientales y el concepto de ambiente no tengan en cuenta la interacción permanente entre el hombre y la naturaleza a través de la cultura, es muy difícil entender que la solución a los mismos no pasa a través de acciones puntuales restringidas a uno de estos componentes como ocurre en el país, por ejemplo en el tratamiento de catástrofes humanitarias relacionadas con el invierno.

Dada la importancia de la visión sistémica de ambiente, el presente proyecto toma la definición de ambiente contenida en la Política Nacional de Educación Ambiental, como: "un sistema dinámico definido por las interacciones físicas, biológicas, sociales y culturales, percibidas o no, entre los seres humanos y los demás seres vivientes y todos los elementos del medio donde se desenvuelven" (Ministerio de Educación Nacional, 2012, p. 28).

En conclusión, el concepto ambiente es básico en la comprensión de los procesos educativos, no solo en el ámbito natural sino de la interacción del hombre con la naturaleza a través de su organización social y cultural. Da la oportunidad de contextualizar el aprendizaje de los estudiantes y comprender la importancia de las interacciones en el uso sostenible de los recursos naturales.

\section{Propuesta metodológica}

En este artículo se presentan los resultados preliminares del proyecto Movilización del concepto ambiente en estudiantes de grado sexto, específicamente la fase de exploración del concepto ambiente. La categorización de los resultados se utilizó como base en el diseño, aplicación y evaluación de una propuesta pedagógica didáctica, cuyo objetivo es la movilización del concepto ambiente hacia la visión sistémica.

El proyecto se desarrolló bajo el paradigma Socio crítico, que considera la realidad como una construcción dinámica, evolutiva y subjetiva. Ya que el conocimiento es un proceso constructivo de comprensión y acción sobre la realidad, el proceso de investigación tiene en cuenta la subjetividad (valores) e intereses del investigador. La investigación es el medio que permite
De acuerdo con Ángel (2013), los problemas ambientales son inherentes a la evolución humana, ya que desde que los primeros homínidos tuvieron la capacidad de organizarse para proveer la caza necesaria para su sustento o de seleccionar las plantas que a través de la agricultura propagó en detrimento de otras cuyo nicho ecológico fue desplazado, el equilibrio ecosistémico empezó a variar. 
Albert (2007) reseña que la investigación acción entiende la teoría y la práctica como un todo inseparable, analizando los hechos desde una perspectiva teórica y de la acción. analizar la realidad, concienciarse de su situación e incorporar dinamismo a la evolución de los valores y la sociedad. (Albert, 2007; Rodríguez, s.f.). Al ser una investigación cualitativa, tiene en cuenta la singularidad del sujeto, estableciendo una interacción física de proximidad empática con los sujetos estudiados (en este caso, los estudiantes), y necesita la comprensión del marco de referencia particular del grupo estudiado (Martínez, 2006).

Dadas las características de este tipo de investigación, no se admite la posibilidad de generalizar los resultados, ya que se limitan a un contexto específico, generalmente limitado por tiempo y espacio. Estos resultados se manifiestan como la determinación de múltiples factores y, por lo tanto, no se limitan a un análisis de causa-efecto (Bonilla y Rodríguez, 1995; Rodríguez, s.f.).

Albert (2007) reseña que la investigación acción entiende la teoría y la práctica como un todo inseparable, analizando los hechos desde una perspectiva teórica y de la acción. En relación con la investigación en el campo educativo, la investigación acción supone comprender la realidad como praxis e implica al docente como investigador a partir de la autorreflexión de su quehacer profesional.

Dadas estas características, la investigación acción enmarcada dentro del paradigma socio-crítico, ofrece la oportunidad de desarrollar el presente proyecto, ya que posibilita la reflexión docente frente a la realidad, no solo de lo que acontece en el aula durante la construcción del conocimiento, sino en el contexto social y cultural en el que se encuentra la institución educativa. Además, es necesario comparar las prácticas en el aula con las teorías del campo pedagógico, generando una mayor coherencia entre ambas y permitiendo el diseño, aplicación y seguimiento permanente de estrategias pedagógicas y didácticas encaminadas a lograr aprendizajes significativos por parte de los estudiantes.

Para la exploración de las concepciones que los estudiantes de grado sexto tienen sobre el concepto de ambiente, se utilizó un instrumento de recolección de información que consiste en el planteamiento de la pregunta ¿Para ti, qué es el ambiente? a partir de la cual se realizaron dos actividades: dibujo individual sobre el concepto ambiente y contestar por escrito la pregunta. Este instrumento se aplicó a estudiantes de grado sexto de la IET Enrique Olaya Herrera, ubicado en el municipio de Guateque. La población de estudiantes de este grado corresponde a 94 alumnos, distribuidos en 3 grados (1, 2 y 3) sin embargo, se implementó e hizo seguimiento a una muestra de 29 estudiantes, correspondientes al grado 6.3 durante el año 2016.

Los estudiantes están distribuidos por género en 17 niñasy 12 niños, con edades entre los 11 y 13 años, provenientes en su mayoría de un colegio privado del municipio y de escuelas unitarias del sector rural. La selección de la muestra es intencional ya que uno de los autores es la directora de grado, lo que ha permitido una mayor interacción con los estudiantes y los padres de familia, 
facilitando la realización de actividades como acompañamiento, compromiso de estudiantes y padres, permisos necesarios en diferentes momentos.

\section{Resultados y análisis preliminar}

La representación gráfica como instrumento para identificar concepciones relacionadas con el ambiente, fue utilizado por Álvarez (2015), Menegaz et al. (2012) y Audicio et al. (2010). En los tres casos, se destaca la riqueza en la información que brinda el dibujo, ya que como lenguaje permite una forma de expresión basada en la vida cotidiana, las condiciones biofísicas y los presupuestos sociales, culturales que rodean a los estudiantes. Además de poder expresar las construcciones mentales acerca del concepto ambiente, también es un ejercicio afectivo ya que a los estudiantes les gusta dibujar.

Giordan y de Vecchi (1988) destacan la dificultad que puede representar para un sujeto tener conciencia sobre sus concepciones, por esta razón, adicional a la correspondiente representación gráfica, se les pidió a los estudiantes redactar un texto escrito acerca del concepto de ambiente, lo que permite volver a reflexionar sobre el concepto dando la oportunidad de hacer consciente los marcos conceptuales que están instalados en cada estudiante.

De acuerdo con los referentes teóricos y los procesos de comparación, relación y clasificación de los textos y las representaciones gráficas de los estudiantes dados como respuesta a la pregunta: “¿para ti, qué es el ambiente?" se establecieron las siguientes categorías y subcategorías:

Categoría Concepto Naturalista: dentro de esta categoría se reúnen las respuestas que excluyen al hombre del concepto de ambiente. Describe el ambiente como un conjunto de factores bióticos y abióticos (componente físico-biológico), que se encuentran en un lugar y momento dado y tiene sus orígenes en la incomodidad que las Ciencias como la Biología y la Ecología tienen ante el hombre, como lo expresa Ángel (2013): “Los ecólogos no han podido encontrar el nicho del hombre. A primera vista, parece un rebelde de la naturaleza” (p. 22). Esta visión es también reforzada a través de los libros de texto, como lo menciona García (s.f.), cuando concluye que: de una muestra de 30 libros de Ciencias Naturales y Medio Ambiente, 97 \% de los textos presentan al ambiente desde una visión físico-natural.

La visión naturalista está presente en los textos, como en el siguiente ejemplo: "Para mí el ambiente es los pájaros como guacamayas, los colibrís, ya que chupan el néctar de las flores para que hallan (sic) más plantas" (estudiante 1). Siete dibujos fueron incluidos en esta categoría, pero solo en un texto no se nombran a los seres humanos, en dos de ellos solo está representado el ambiente por el dibujo sin texto que los acompañe; mientras que los cuatro restantes hacen alusión a la exclusión del hombre del concepto. Aunque los dibujos no presentan al ser humano o modificaciones antrópicas que permitan inferir su presencia, en los textos se hace referencia a la causa de su exclusión: el efecto negativo sobre 
La presencia del ser humano puede ser explícita o se puede inferir de la presencia de modificaciones antropomórficas. de esta categoría, se encuentran todas las respuestas que incluyen al hombre tampoco son incluidas dentro del concepto.

Categoría antropocentrista: dentro en el dibujo o en los textos, pero no reconoce las interacciones que se establecen entre el componente físicobiológico y los componentes sociales y culturales del mismo. La presencia del ser humano puede ser explícita o se puede inferir de la presencia de modificaciones antropomórficas. Este concepto de ambiente desde la visión antropocentrista, tiene como base el paradigma del Pensamiento Positivista Mecanicista, a partir del cual es necesario encontrar la objetividad de quien observa alejándose de lo observado. El método racional de entender la realidad, originó la ruptura de una visión de conjunto y ha producido el alejamiento del hombre de la naturaleza (Carrizosa, 2000; Capra, 2003; González, 2006). Este alejamiento se refleja en lo que González ha denominado medio ambiente:

[...] el concepto de medio ambiente se ha utilizado, generalmente, para señalar el ambiente como el entorno biofísico que rodea o sirve de escenario a la actividad humana, $y$ es usado como medio, elemento o insumo para satisfacer las necesidades humanas que, de hecho, más que meramente naturales, son culturales e históricas. (p. 22).

Del total de 21 estudiantes, ocho de ellos presentan respuestas que entran dentro de la categoría antropocentrista. Sin embargo, algunas diferencias, especialmente en los textos, han permitido establecer las siguientes subcategorías:

Ambiente como lugar: esta subcategoría se representa en textos como: "Para mí el ambiente es todo lo que nos rodea, los árboles, los animales y muchas cosas

las condiciones del ambiente. Como se La estudiante 5 manifiesta: "Mi dibujo expresa naturaleza porque en el dibujo ellos tienen que ver con el medio ambiente, dibuje (sic) palomas porque ellas viven en la naturaleza un lugar de relajada, no hay personas porque la ayoría de personas la contaminan". En este caso, la mayoría de las personas porcentaje que no lo hace, aun así, Conocimiento, el efecto del ser humano ). La palabra siempre demuestra la y niega la posibilidad de otros tipos de relación entre hombre y naturaleza. 
más” (estudiante 15) en el cual, a pesar de solo nombrar factores bióticos, se incluye al ser humano al determinar que es todo lo que nos rodea. Sin embargo, también se hace referencia al ser humano distante de la naturaleza al referirse a ella como entorno que rodea al ser humano.

Cuando se hace referencia al ambiente como un lugar, también se incluyen los efectos negativos del hombre sobre la naturaleza. Sin embargo, no se excluye del todo la presencia humana, por ejemplo: "Para mí el ambiente es un lugar muy tranquilo y lleno de paz donde hay árboles, plantas, animales, etc. pero casi no habitan personas porque ellos contaminan el medio ambiente botando basura en los ríos no reciclando" (estudiante 10). En este caso, la estudiante duda entre incluir al ser humano o no dentro del concepto, algunas personas habitan a pesar de contaminar, es decir el ambiente es un lugar hermoso hasta que las personas lo contaminan.

\section{Subcategoría Ambiente como lugar donde habita el hombre: en esta subcategoría se encuentran las respuestas en las cuales el ambiente es un entorno donde las personas viven, un lugar de ubicación, como claramente lo expresa la estudiante número 11: "mi dibujo tiene casa porque si no hubieran casa donde (sic) viviríamos, hay también flores de la naturaleza, también hay aves, arboles (sic), montañas, mejor dicho plantas”. Sin embargo, en su dibujo se observan varias casas y caminos que las unen, lo cual permite inferir una relación entre personas, mas no interacciones del ser}

humano con la naturaleza u otro tipo de interacción sino simplemente el "dónde viviríamos".

\section{Subcategoría el hombre debe cuidar} del ambiente: esta subcategoría se asimila con la subcategoría pactada (categoría antropocéntrica) definida por Álvarez (2015) cuando establece: "La categoría se relaciona con una actitud ética de los seres humanos los cuales deben hacerse responsables de los daños cometidos al ambiente" (p. 34). La estudiante 13 presenta esta actitud ética en su texto: "Este dibujo representa para mí el cuidado que los seres humanos deberíamos tener con el medio ambiente en cambio por botar cosas a los ríos es que el ambiente se contamina y no vuelve a ser el mismo por eso deberíamos aprender a tratar mucho mejor a la naturaleza". Esta respuesta también denota al ambiente como algo exterior al hombre, que debe ser cuidado para evitar los daños negativos de la interacción ser humano-naturaleza.

\section{Categoría aproximaciones al ambiente como sistema: aunque} ningún estudiante expresa en sus dibujos o textos, o en la combinación de ambos, un concepto de ambiente en el cual se establezcan de forma explícita, los componentes físico - biológico (factores bióticos y abióticos), sociales y culturales, así como las interacciones que se establecen entre ellos, es posible establecer aproximaciones al ambiente como sistema por la presencia de dos o más componentes, relaciones y alguna interacción entre ellos en seis de los veinte dibujos y textos interpretados. Dentro de las diferentes
Cuando se hace referencia al ambiente como un lugar, también se incluyen los efectos negativos del hombre sobre la naturaleza. 
Los resultados obtenidos en la exploración inicial sobre las concepciones de ambiente en los estudiantes de grado sexto, no difieren de las obtenidas en investigaciones reportadas en los antecedentes. aproximaciones, se establecieron las siguientes subcategorías:

Subcategoría ser humano parte del ambiente: aunque en cinco de los veinte dibujos se evidencia la presencia de uno o dos seres humanos, solo dos estudiantes manifiestan al ser humano como parte del ambiente. El estudiante 17 escribió en su texto sobre la definición de ambiente: "Puse unas personas por que (sic) es del medio ambiente, una casa porque pertenece al medio ambiente, un gato porque es del medio ambiente, unos peces porque es del medio ambiente, unos árboles porque me gustan porque son del medio ambiente", mientras que la estudiante 16 manifiesta: "El significado de mi dibujo es: "Que todo la naturaleza sin nada de edificios es hermoso ya que todos los animales, plantas y el agua pura; nos dan la vida porque nuestro corazón está lleno de vida salvaje ya que nuestro ser y nuestra especie es y viene de la naturaleza”. En el primer caso, el estudiante establece que "puse unas personas por que (sic) es del medio ambiente", mientras que la estudiante 16 incluye a nuestra especie además de nuestro ser. El hecho de considerar a los seres humanos como parte de la naturaleza establece una continuidad entre el entorno $\mathrm{y}$ el individuo, lo cual seguramente permitirá que los estudiantes movilicen sus conceptos hacia la comprensión del ambiente como una construcción social e histórica (González, 2006).

Subcategoría ambiente como componentes y relaciones entre componentes: en algunos dibujos y textos, se hacen evidentes los diferentes componentes, pero no se establecen interacciones entre ellos. La mayor parte de los dibujos presentan la relación del ser humano con el componente físicobiológico (asimilable con la naturaleza) por medio de las intervenciones antropomórficas (casas, caminos, cercas) y las relaciones entre el componente social con la naturaleza, especialmente en la parte económica, ya que se representan formas de producción como cultivos o explotaciones animales que garantizan la generación de ingresos.

\section{Consideraciones finales}

Los resultados obtenidos en la exploración inicial sobre las concepciones de ambiente en los estudiantes de grado sexto, no difieren de las obtenidas en investigaciones reportadas en los antecedentes. Priman las concepciones bajo la categoría antropocentrista del ambiente como un lugar del cual se obtienen recursos, seguido muy de cerca por la categoría naturalista en la cual el ambiente está formado por elementos naturales (bióticos y abióticos).

Estas concepciones son construidas, en gran parte, en el mismo aula de clases, ya que el PRAE se desarrolla en este grado por medio de acciones puntuales y descontextualizadas, en los planes de estudio no aparece explícito el concepto de ambiente y los libros de texto tampoco establecen la visión sistémica del mismo.

Es necesario tener en cuenta las concepciones iniciales de los estudiantes en la planificación y desarrollo de las actividades de aula, como una 
base importante para constatar su movilización a través del proceso de construcción de conocimientos. Estos cambios dan las pautas para hacer las adaptaciones a las actividades $u$ objetivos de las estrategias pedagógicas didácticas planteadas por la docente.

El proceso llevado a cabo y los resultados obtenidos hasta el momento validan la importancia de esta propuesta pedagógica y didáctica, ya que determina la movilización de concepciones como una herramienta importante en la construcción de conocimientos significativos para los estudiantes

Finalmente, la movilización del concepto ambiente hacia la visión sistémica, permite la construcción, aplicación y cualificación conceptual del Proyecto Ambiental Escolar para el grado sexto, lo cual permite la formación en valores, pensamiento crítico y la aplicación de los conocimientos en el contexto que propone la Educación Ambiental.

\section{Referencias bibliográficas}

Albert, M. (2007). La investigación educativa: claves teóricas. Madrid: McGrawHill.

Álvarez, Y. (2015) Concepciones de ambiente en estudiantes de educación media del Colegio Carlos J. Huelgos de Ibagué. (Tesis de Maestría) Universidad del Tolima. Tolima, Colombia. Recuperado de http://repository.ut.edu.co/ bitstream/001/1426/1/RIUT-BHA-spa-2015-Concepciones $\% 20 \mathrm{de} \% 20$ ambiente $\% 20$ en $\% 20$ estudiantes $\% 20 \mathrm{de} \% 20$ educaci $\% \mathrm{C} 3 \% \mathrm{~B} 3 \mathrm{n} \% 20$ media $\% 20$ del\%20colegio\%20carlos\%20j.\%20huelgos\%20de\%20ibague.pdf

Ángel, A. (2013). El Reto de la Vida. Ecosistema y Cultura, Una Introducción al Estudio del Medio Ambiente. (2a ed.). Recuperado de: www.augustoangelmaya.com

Audicio, A., Enrico, A., \& Rivarosa, A. (2010). Análisis de las concepciones sobre Ambiente a partir de representaciones gráficas: Una experiencia de formación docente. Revista de Educación en Biología. 13 (1). Recuperado de: http://www. revistaadbia.com.ar/ojs/index.php/adbia/article/viewFile/172/116

Bonilla, E., \& Rodríguez, P. (1995). Más allá del dilema de los métodos. Bogotá: Editorial Norma.

Capra, F. (2003). La trama de la vida. Una perspectiva de los sistemas vivos. (5 ed.). Barcelona: Anagrama.

Carrizosa, J. (2000). ¿Qué es ambientalismo? -La visión ambiental compleja. Santafé de Bogotá: Centro de estudios ambientales Universidad Nacional de Colombia

Castaño, A. (2014). Prácticas de Escritura en el Aula. Orientaciones Didácticas para Docentes. Bogotá: Ministerio de Educación Nacional. Recuperado de: http:// www.colombiaaprende.edu.co/html/micrositios/1752/articles-341021_ recurso_1.pdf

El proceso llevado a cabo y los resultados obtenidos hasta el momento validan la importancia de esta propuesta pedagógica y didáctica 
FLóREZ, G. (2012). Saberes y prácticas de la EA en los escenarios escolares del Municipio de Nobsa, Boyacá. (Tesis de Maestría). Universidad Pedagógica y Tecnológica de Colombia, Tunja, Boyacá.

García, S. (S.F). El Concepto de Ambiente en los Libros de Texto. Bio-grafía Escritos sobre la Biología y su Enseñanza. Edición Extra-Ordinaria. Recuperado de http://revistas. pedagogica.edu.co/index.php/bio-grafia/article/viewFile/2393 /2243

Giordan A., \& VECCHI G DE. (1988). Los orígenes del saber. De las concepciones personales a los conceptos científicos. Sevilla. Diada Editora.

Giordan A. (1996) . ¿Cómo ir más allá de los modelos constructivistas? La utilización didáctica de las concepciones de los estudiantes. Investigación en la escuela. (28).

González, E. (s.f.) Las Concepciones del Medio Ambiente en Estudiantes de Nivel Superior. Revista Iberoamericana de Educación. Recuperado de http://rieoei.org/ deloslectores/602Gonzalez.PDF

GonzÁLEZ, F. (2006). En busca de caminos para la comprensión de la problemática ambiental. (La escisión moderna entre cultura y naturaleza). Bogotá: Pontificia Universidad Javeriana.

Menegaz, A., Cordero, S., \& Mengascini, A. (2012). Sistematización de una experiencia de educación ambiental en la formación docente continua: representaciones, ambiente y análisis colaborativo. Revista Electrónica de Enseñanza de las Ciencias. 11 (3). Recuperado de https://www.researchgate. net/publication/234842904_Sistematizacion_de_una_experiencia_de_ educacionambiental_en_la_formacion_docente_continuarepresentaciones_ ambiente_y_analisis_colaborativo

Ministerio de Educación Nacional. (2012). Política Nacional de Educación Ambiental. $\operatorname{SIN} A$. Bogotá: Stilo Impresores

Ministerio de Educación Nacional. Corporación Autónoma Regional de Boyacá. (s.f.). Informe Final Diplomado: Educación Ambientaly Contexto Institucional: Estrategia Transversal, para la Cualificación de la Gestión Ambientaly su Proyección, en el Departamento de Boyacá.

Molano, R. (2011) Criterios para la lectura del proyecto ambiental escolar (PRAE) del centro educativo Suarapawa del municipio de Nobsa, Boyacá. Un estudio de caso. (Tesis de Maestría). Universidad Pedagógica y Tecnológica de Colombia, Tunja, Colombia.

NiÑo, L. (2013). Estudio de caso. Una estrategia para la enseñanza de la Educación Ambiental. (Tesis de Maestría). Universidad Pedagógica y Tecnológica de Colombia, Tunja, Colombia.

Rodriguez, J. (s.f.). Paradigmas Enfoques y Métodos en la investigación Educativa. s.c., s.e.

Rosas, R., \& Sebastián, C. (2008). Piaget, Vigotski y Maturana. Constructivismo a tres voces. Buenos Aires: Aique, Grupo Editor.

Venegas, C. (2015). Movilización de las Concepciones Docentes sobre la Enseñanza de la Oralidad en el Aula de Lengua Castellana. (Tesis de Maestría). Universidad Distrital Francisco José de Caldas, Bogotá, Colombia. 